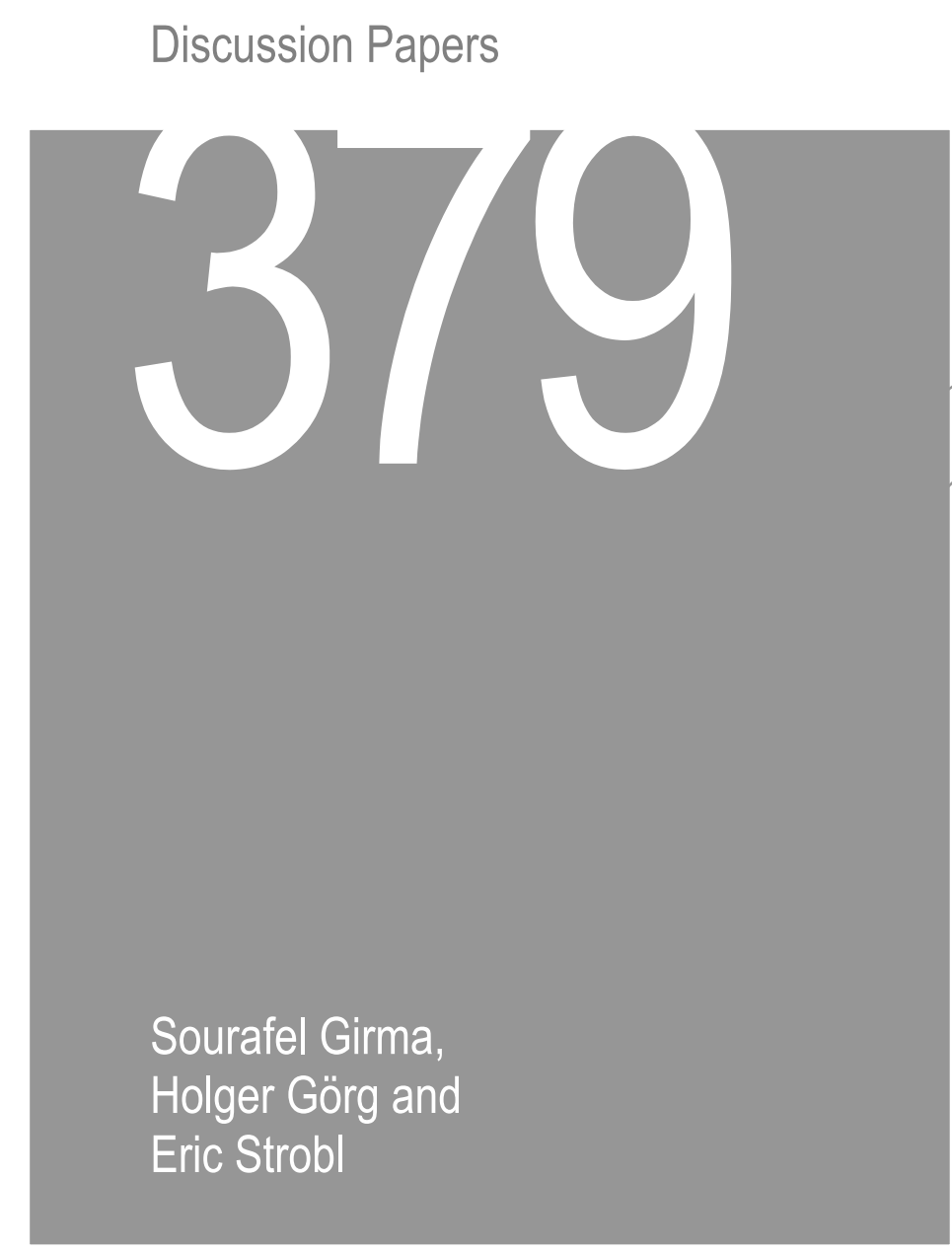

Exports, international investment, and plant performance:

Evidence from a non-parametric test

Berlin, November 2003 
Opinions expressed in this paper are those of the author and do not necessarily reflect views of the Institute.

DIW Berlin

German Institute

for Economic Research

Königin-Luise-Str. 5

14195 Berlin,

Germany

Phone +49-30-897 89-0

Fax $\quad+49-30-89789-200$

www.diw.de

ISSN 1619-4535 


\title{
Exports, international investment, and plant performance: Evidence from a non-parametric test
}

\author{
Sourafel Girma \\ University of Leicester \\ Holger Görg \\ University of Nottingham and DIW Berlin \\ Eric Strobl \\ Université catholique de Louvain
}

\begin{abstract}
This paper compares the performance of purely domestic plants, domestic exporters and domestic multinationals. For our empirical analysis we utilise a non-parametric approach based on the principle of first order stochastic dominance. We find that the distributions for multinationals dominate that of domestic exporters and non-exporters, while we do not find clear differences in plant performance between domestic exporters and non-exporters.
\end{abstract}

Keywords: exporting, FDI, multinationals, productivity, profitability, plant heterogeneity

JEL classification: F23, F14, D21

Acknowledgements: The authors are grateful to Forfás, in particular Marcus Breathnach, for the provision of the data. Holger Görg gratefully acknowledges financial support through the Leverhulme Trust (Grant No. F114/BF). Eric Strobl is grateful for a European Commission Marie Curie Fellowship. 


\section{Introduction}

The empirical findings of substantial heterogeneity in firm performance across exporters and non-exporters (e.g., Clerides et al., 1998, Bernard and Jensen, 1999, Wagner, 2002) have spun off a number of recent theoretical papers, attempting to explain this plant or firm level heterogeneity in a formal setting. Examples of such models are Melitz (2003) and Bernard et al. (2003), both of which allow for plant level heterogeneity in efficiency and find that in equilibrium more efficient firms select into exporting, while less efficient ones serve the local market only.

In an extension of these models, Helpman et al. (2003) allow for three modi operandi for firms: serving only the domestic market, exporting, or investing abroad to sell on the foreign market (FDI). They show that the most efficient firms will engage in FDI while the least efficient will operate only in the domestic market. Firms with medium efficiency levels will become exporters, but not undertake FDI. While this clear-cut prediction emerges from the theory, one may not expect it to hold in empirical data. For example, due to uncertainty, firms may not immediately enter into exporting even if they have the necessary level of efficiency.

We use plant level data to compare productivity and profitability measures across these three groups of establishments. There has been little work in this area, as most micro level datasets do not allow, for a given home country, to distinguish between firms that only service the local market, firms that export, and firms that choose to invest abroad. ${ }^{1}$ Our dataset provides information for manufacturing plants in the Republic of Ireland on all three

\footnotetext{
${ }^{1}$ One recent study we are aware of that compares productivity for domestic firms and domestic multinationals is by Doms and Jensen (1998) for the US. There has, however, been a multitude of studies comparing productivity
} 
of these dimensions. Moreover, in the comparison of the performance measures across the three firm types we do not just look at one part of the distribution, i.e., the mean, as is the case in most of the related literature cited above. Rather, we test for differences in all moments of the distribution using a non-parametric approach based on the concept of first order stochastic dominance. $^{2}$

Ireland serves as an interesting case study for a number of reasons. Firstly, on average, almost 60 percent of domestic firms export and the average export intensity in manufacturing industries (averaged over exporters and non-exporters) is around one-third of output (Ruane and Sutherland, 2002). Secondly, while the Irish industrial structure is significantly influenced by foreign multinationals, Irish outward FDI has recently also increased substantially (Görg, 2000). Hence, we would expect a significant number of domestic exporters as well as domestic multinationals in the economy. Thirdly, the Irish data set is one of a (to the best of our knowledge) limited number of comprehensive micro level surveys collecting information on exporting and outward investment at the plant level.

\section{Methodology}

For our analysis we invoke the concept of first order stochastic dominance which allows us to compare and rank the distributions of measures of plant performance. Let $F$ and $G$ denote two cumulative distribution functions for two comparison groups, e.g., productivity of domestic multinationals and domestic exporters. First-order stochastic dominance of $F$

in domestic firms and foreign-owned multinationals located in the host country, see, for example, Girma at al. (2001) for the UK, Doms and Jensen (1998) for the US and Globerman (1994) for Canada.

${ }^{2}$ See Delgado et al. (2002) for an application of this approach in their comparison of productivity between exporters and non-exporters. The paper by Girma et al. (2003) is more closely related to our paper, also appealing to the Helpman et al. (2003) model. However, their main comparison is between UK non-exporters, UK exporters and foreign multinationals, given the absence of information on UK multinationals in their dataset. They attempt to construct data on UK multinationals from other datasources, but this does not give them a 
with respect to $G$ is defined as $F(z)-G(z) \leq 0$ uniformly in $z \in \mathfrak{R}$, with strict equality for some $z$. Since this considers all moments of the distribution it is a stricter test of productivity differences than just comparing mean levels of productivity. In the context of this paper these tests therefore encompass the possibility that establishments of the same productivity level may choose different forms of commerce, but restrict the test such that there must be statistically robust differences between the distributions. That is, the degree of uncertainty in behaviour cannot be too large so that the structure of commerce and plant heterogeneity are no longer meaningfully related.

In order to implement the comparison we follow Delgado et al. (2002) and adopt the nonparametric one-sided and two-sided Kolmogorov - Smirnov (KS) tests. ${ }^{3}$ The two-sided KS statistic tests the hypothesis that both distributions are identical, and the null and alternative hypotheses can be expressed as:

$$
H_{0}: F(z)-G(z)=0 \forall z \in \mathfrak{R} \text { vs. } H_{1}: F(z)-G(z) \neq 0 \text { for some } z \in \mathfrak{R}
$$

By contrast, the one-sided test of stochastic dominance can be formulated as :

$$
H_{0}: F(z)-G(z) \leq 0 \forall z \in \mathfrak{R} \text { vs. } H_{1}: F(z)-G(z)>0 \text { for some } z \in \mathfrak{R}
$$

Hence, in order to conclude that F stochastically dominates $G$ we need to reject the null hypothesis for the two sided test, but not reject the null for the one sided test.

The KS test statistics for the two and one sided tests are, respectively

$$
\begin{aligned}
& K S_{2}=\sqrt{\frac{n \cdot m}{N}} \max _{1 \leq i \leq N}\left\{F_{n}\left(z_{i}\right)-G_{m}\left(z_{i}\right)\right\} \\
& K S_{1}=\sqrt{\frac{n \cdot m}{N}} \max _{1 \leq i \leq N}\left|F_{n}\left(z_{i}\right)-G_{m}\left(z_{i}\right)\right|
\end{aligned}
$$

complete coverage of all UK MNEs. In contrast, our dataset allows the identification of all domestic multinationals. Furthermore, their data is company level, not plant level as in our analysis. 
where $n$ and $m$ are the sample sizes from the empirical distributions of $F$ and $G$ respectively, and $N=n+m$.

\section{Data}

Our data come from the Annual Business Survey of Economic Impact (ABSEI), an annual survey of a large sample of manufacturing plants in the Republic of Ireland. Plants are included in this survey if they have at least 10 employees, but are not necessarily dropped if they fall below this threshold. The coverage is about 60 to 80 per cent of the targeted population. Data from the ABSEI are available for the year $2000 .^{4}$

The data set provides plant level data on, inter alia, nationality of ownership, output, exports, employment and expenditure on labour and other inputs for Irish manufacturing plants. ${ }^{5}$ What makes the data most interesting from our point of view is an indicator variable that is equal to one if a plant has "any overseas offices or distribution facilities". Taking all this information together, we can deduct from the data whether a domestic firm is a multinational, an exporter, or just a plant serving the local market, making our datasource quite unique in an international comparison.

We calculate and compare three measures of establishment performance: (1) sales per employee, (2) value added per employee, and (3) net profit per employee. ${ }^{6}$ The first two measures are essentially indicators of labour productivity, while the third measure provides an indicator of financial performance. Value added is defined as sales minus intermediate input purchases, while net profits are value added minus labour cost and other expenditure. All

\footnotetext{
${ }^{3}$ See, for example, Conover (1999) for a discussion.

${ }^{4}$ Strictly speaking, the ABSEI also includes information for 1999 but this is included in the 2000 survey via retrospective questions.

${ }^{5}$ Forfás defines a plant as foreign owned if 50 percent or more of its shares are held by foreign owners.
} 
three performance indicators are calculated relative to the two-digit industry mean to ensure transitivity among comparisons and are in logged values. ${ }^{7}$

\section{Results}

In what follows below, we label domestic non-exporters DN, domestic exporters DE and domestic multinationals MN. Table 1 provides some summary statistics on the three performance measures for the three groups of firms separately. It is clear that the means for $\mathrm{MN}$ are higher than the means for either $\mathrm{DE}$ or $\mathrm{DN}$ for all three measures of plant performance. However, note that the standard deviations for $\mathrm{MN}$ are also highest, thus suggesting that the largest heterogeneity in plant performance is among domestic multinationals. From the simple means it is not obvious that domestic exporters outperform domestic non-exporters.

\section{[Table 1 here]}

These summary statistics, of course, only look at two moments of the performance measure distribution, namely the mean and standard deviation. A simple preliminary manner of examining differences of the entire distribution of the performance measures is to plot cumulative distribution functions (cdf) and compare these across the three groups of establishments. We do this here for the value added measure only in Figures 1 through 3, but emphasize that similar visual difference across the three groups were also observed for the other two measures. ${ }^{8}$ Accordingly, while there appear to be no differences in the cumulative

\footnotetext{
${ }^{6}$ One should note that we cannot calculate total factor productivity since there is no reliable estimate of capital stock at the plant level available in the data.

${ }^{7}$ This also helps to mitigate concerns that performance differences simply reflect differences in the sectoral composition of the three firm types.

${ }^{8}$ Detailed results are available from the authors.
} 
distribution between DN and DE plants, that of MN plants lies clearly to right of these two groups.

In order to test specifically for differences in all moments of the distribution we calculate the above described KS tests of first order stochastic dominance, the results of which for all three measures are reported in Table 2. These show that we cannot reject the hypothesis of identical distributions of all three performance measures for exporters relative to non-exporters. Thus, these results for the Irish case are not fully in line with the previous empirical literature (e.g., Clerides et al., 1998, Bernard and Jensen, 1999, Wagner, 2002), which finds substantial differences in productivity between exporters and non-exporters.

The comparisons of Irish MNEs with exporters or non-exporters are, by contrast, in line with the predictions of the Helpman et al. (2003) model. Specifically, the KS test statistics in Table 2 suggest that the distributions of both measures of labour productivity and profits per employee of multinationals stochastically dominate those of both non-exporters and exporters. Hence, we find statistically significant productivity differences between domestic multinationals and both domestic exporters and non-exporters.

[Table 2 and Figures 1-3 here]

\section{Conclusions}

This paper compares labour productivity and profitability differences across purely domestic plants, domestic exporters and domestic multinationals in Ireland. Thus, our paper provides empirical evidence closely related to a number of recent theoretical papers dealing with heterogeneity at the plant level across these three types of establishments. For our empirical analysis we utilise a non-parametric approach based on the principle of first order stochastic dominance. Comparing the cumulative distributions of the measures of plant 
performance across the three types of plants we find that the distributions for multinationals dominate that of domestic exporters and non-exporters, while we do not find clear differences in plant performance between domestic exporters and non-exporters. The result that multinationals dominate the other two groups of plants is in line with the theoretical model by Helpman et al. (2003). 


\section{References}

Bernard A.B., Eaton J., Jensen B. and S.S. Kortum (2003), "Plants and productivity in international trade, American Economic Review, Vol. 93, pp. 1268-1290.

Bernard, A.B. and Jensen, J.B. (1999), "Exceptional exporter performance: Cause, effect, or both?”, Journal of International Economics 47, 1-25.

Clerides, S., Lach, S. and Tybout, J. (1998), "Is learning by exporting important? Microdynamic evidence from Columbia, Mexico and Morocco", Quarterly Journal of Economics $113,903-948$.

Conover W. J. (1999), Practical Nonparametric Statistics, John Wiley \& Sons.

Delgado, M. A., Farinas, J. C., and S. Ruano (2001), "Firm productivity and export markets: A non-parametric approach", Journal of International Economics 57(2), 397-422.

Doms, M.E. and J.B. Jensen (1998), "Comparing wages, skills, and productivity between domestically and foreign-owned manufacturing establishments in the United States", in R. Baldwin, R. Lipsey and J.D. Richardson (eds.), Geography and Ownership as Bases for Economic Accounting, Chicago: Chicago University Press, 235-255.

Girma, S., D. Greenaway and K. Wakelin (2001), "Who benefits from Foreign Direct Investment in the UK?", Scottish Journal of Political Economy 48, 119-133.

Girma, S., R. Kneller and M. Pisu (2003), "Exports versus FDI: An empirical test", mimeo, University of Nottingham.

Globerman, S., J.C. Ries and I. Vertinsky (1994), "The economic performance of foreign affiliates in Canada", Canadian Journal of Economics 27, 143-156.

Görg, H. (2000): "Irish Outward Investment in the US: Evidence and Further Issues", Journal of the Statistical and Social Inquiry Society of Ireland 30, 33-52.

Helpman E., Melitz M.J., and S.R. Yeaple (2003), "Export versus FDI with heterogeneous firms", American Economic Review, forthcoming.

Melitz M.J. (2003), “The impact of trade on intra-industry reallocations and aggregate industry productivity, Econometrica, forthcoming.

Ruane, F. and J. Sutherland (2002), "Globalization, Europeanization and Trade in the 1990s: Export Responses of Foreign and Indigenous Manufacturing Companies", Trinity Economic Paper 02/04, Trinity College Dublin.

Wagner, J. (2002), "The causal effects of exports on firm size and labor productivity: First evidence from a matching approach", Economics Letters 77, 287-292. 
Table 1: Means and standard deviations for DN, DE and MN

\begin{tabular}{|c|c|c|c|}
\hline & $\mathrm{DN}$ & $\mathrm{DE}$ & $\mathrm{MN}$ \\
\hline \multicolumn{4}{|l|}{ Absolute values } \\
\hline \multirow{2}{*}{ sales/employee } & 87.837 & 96.493 & 122.397 \\
\hline & 80.191 & 101.166 & 131.755 \\
\hline \multirow[t]{2}{*}{ value added / employee } & 66.580 & 74.418 & 94.797 \\
\hline & 74.008 & 89.866 & 121.807 \\
\hline \multirow{2}{*}{ profits / employee } & 33.320 & 32.370 & 43.199 \\
\hline & 41.715 & 57.991 & 77.100 \\
\hline \multicolumn{4}{|c|}{ log value relative to industry mean } \\
\hline \multirow[t]{2}{*}{ sales/employee } & 0.895 & 0.955 & 1.249 \\
\hline & 0.688 & 0.700 & 1.258 \\
\hline \multirow[t]{2}{*}{ value added / employee } & 0.872 & 0.949 & 1.295 \\
\hline & 0.814 & 0.827 & 1.663 \\
\hline \multirow[t]{2}{*}{ profits / employee } & 0.969 & 0.943 & 1.188 \\
\hline & 0.888 & 0.887 & 1.626 \\
\hline
\end{tabular}


Table 2: Kolmogorov-Smirnov tests for comparison of DN, DE and MN

Panel A: $\log$ (sales / employee)

\begin{tabular}{|c|c|c|c|}
\hline$F v s G$ & $F=G$ & $F \leq G$ & $G \leq F$ \\
\hline DE vs DN & 0.0797 & 0.0797 & -0.0279 \\
& $(0.142)$ & $(0.071)$ & $(0.723)$ \\
\hline MN vs DN & $0.2430^{* *}$ & $0.2430^{* * *}$ & 0.0000 \\
& $(0.000)$ & $(0.000)$ & $(1.000)$ \\
\hline MN vs DE & $0.1855^{* *}$ & $0.1855^{* *}$ & 0.0000 \\
& $(0.000)$ & $(0.000)$ & $(0.100)$ \\
\hline
\end{tabular}

Panel B: log (value added / employee)

\begin{tabular}{|c|c|c|c|}
\hline$F v s G$ & $F=G$ & $F \leq G$ & $G \leq F$ \\
\hline DE vs DN & 0.0612 & 0.0367 & -0.0612 \\
& $(0.417)$ & $(0.570)$ & $(0.211)$ \\
\hline MN vs DN & $0.1373^{*}$ & $0.1373^{* *}$ & -0.0105 \\
& $(0.012)$ & $(0.006)$ & $(0.970)$ \\
\hline MN vs DE & $0.1305^{* *}$ & $0.1305^{* *}$ & -0.0037 \\
& $(0.005)$ & $(0.002)$ & $(0.995)$ \\
\hline
\end{tabular}

Panel C: $\log$ (profit/employee)

\begin{tabular}{|c|c|c|c|}
\hline$F v s G$ & $F=G$ & $F \leq G$ & $G \leq F$ \\
\hline DE vs DN & 0.0767 & 0.0843 & -0.0147 \\
& $(0.172)$ & $(0.086)$ & $(0.914)$ \\
\hline MN vs DN & $0.2124^{* *}$ & $0.2124^{* *}$ & -0.0081 \\
& $(0.000)$ & $(0.000)$ & $(0.982)$ \\
\hline MN vs DE & $0.1678^{* *}$ & $0.1678^{* *}$ & -0.0103 \\
& $(0.000)$ & $(0.000)$ & $(0.963)$ \\
\hline
\end{tabular}

Notes:

number of observations: DN: 307; DE 647; MNE 246

p-values in parentheses

$*$ Significant at $10 \%, * *$ significant at $5 \%, * * *$ significant at $1 \%$ confidence interval 
Figure 1: VAD/Employee Level Differences between DN and DE

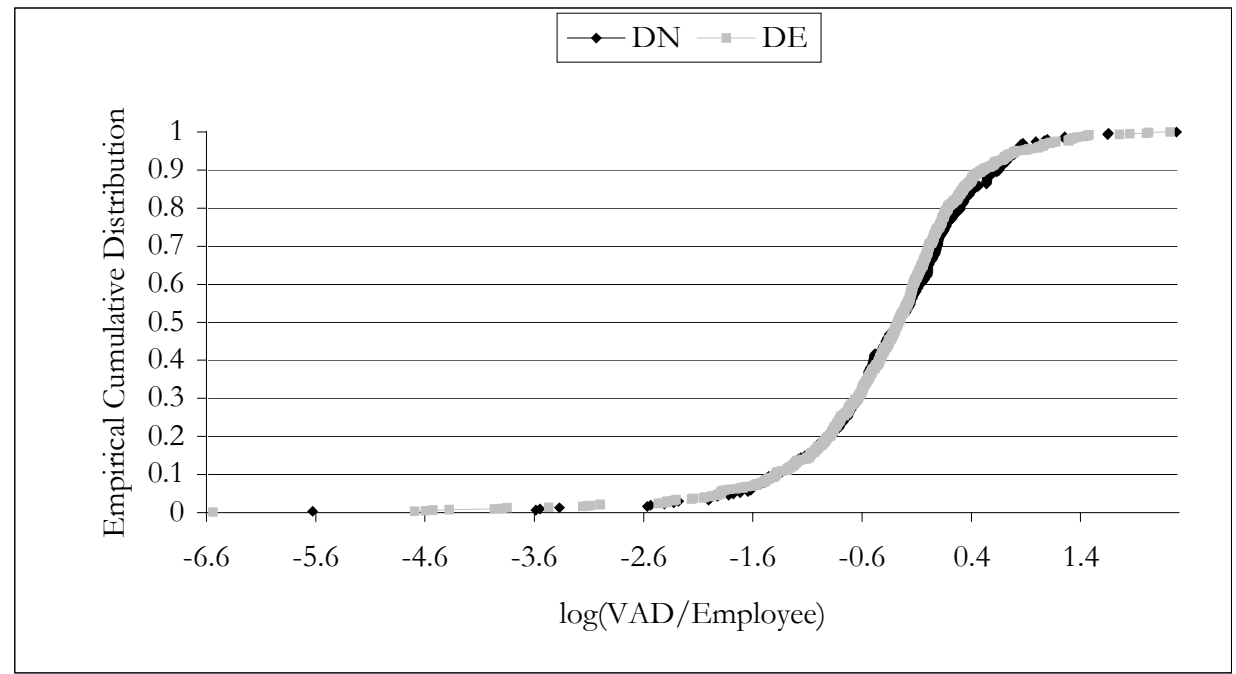

Figure 2: VAD/Employee Level Differences between DN and MN

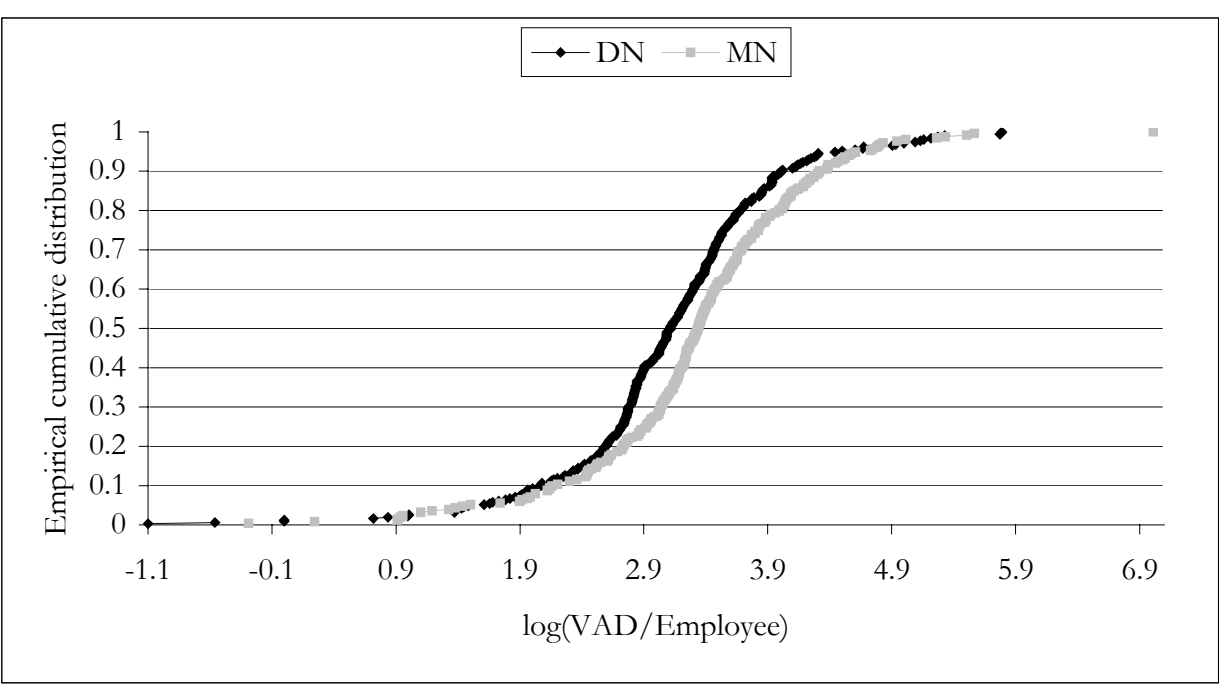


Figure 3: VAD/Employee Level Differences between DE and MN

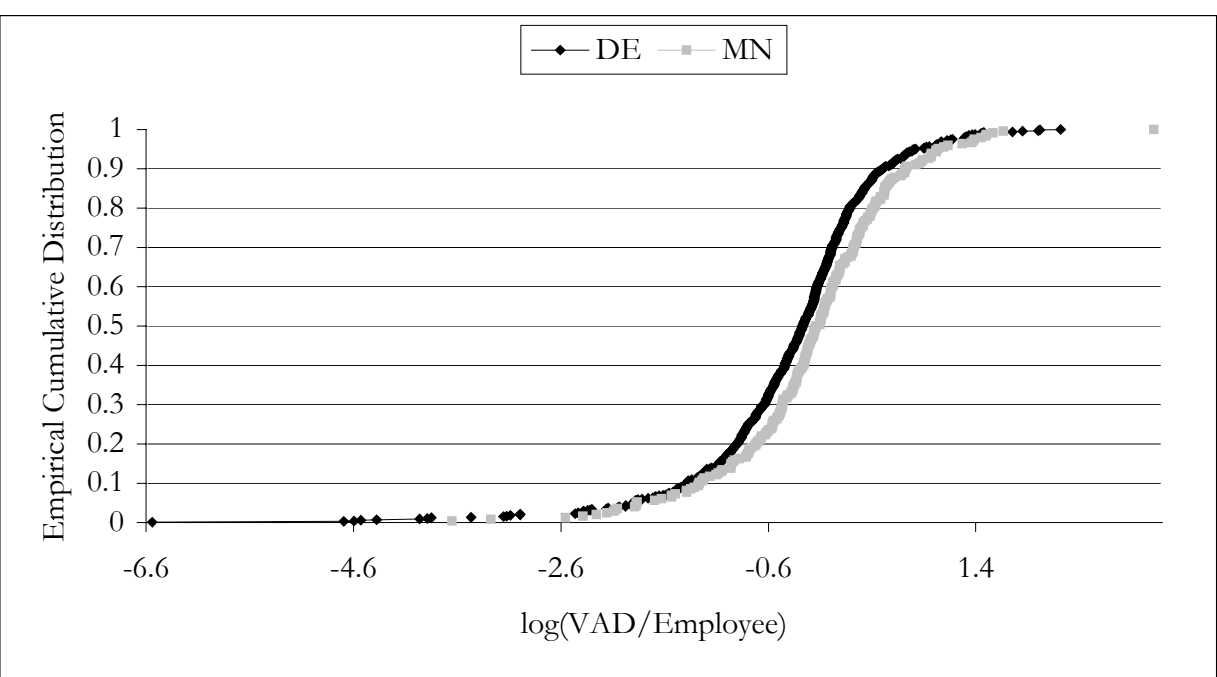

